\title{
Not neutral: reimagining antiracism as a professional competence
}

\author{
Saroo Sharda MBChB MMEd, Aruna Dhara MD MPH, Fahad Alam MD MHSc
}

Cite as: CMAJ 2021 January 18;193:E101-2. doi: 10.1503/cmaj.201684

$\mathbf{R}$ acial justice was a dominant theme of 2020. The medical community has grappled with a long history of racial injustice, and it was heartening to see medical institutions acknowledge their obligations to antiracism in reaction to high-profile events. Although some physicians joined Black Lives Matter protests or became engaged in antiracist movements, others may have hesitated, concerned that their hospitals and universities would view such activism as unprofessional behaviour. Such conflicts expose a tension in the CanMEDS framework. According to the framework, physicians, as professionals, must "reflect contemporary society's expectations ... which include ... promotion of the public good ... and values such as ... humility, respect for diversity. In their role as health advocates, they are called to promote the health of the communities they serve." If advocating for racial justice is in line with our professional values, how can there be any hesitation in doing so? Yet, in practice, the role of professional can undermine that of advocate for physicians because our current understanding of professionalism is not race neutral. In this article, we discuss the ways that race factors into interprofessional interactions and inpatient care, and argue that a change to our current understanding of professionalism is critical to operationalizing the recent commitments of hospitals and universities to antiracist work.

A White, cisgender, apolitical, heteronormative man not living with a disability has long been upheld as the model "professional," in line with a system that centres on "a series of characteristics that institutionalize whiteness and Westernness as both normal and superior to other ethnic, racial and regional identities and customs." ${ }^{2}$ However, this is not in line with the profession's stated values. ${ }^{1}$ Professionalism is how physicians hold themselves accountable to patients and society. As such, it is imperative that physicians engage with larger conversations challenging what constitutes professional behaviour. ${ }^{2}$ In fact, we argue that our professional accountability to society demands our commitment to a more just, and thereby more healthy, society.

In a recent debate article, Boroumand and colleagues described uptake of the advocate role in medical education as "underwhelming," ${ }^{3}$ suggesting that at least part of the reason for its relatively weak application in medical education is a lack of

\section{KEY POINTS}

- The CanMEDS roles of professional and health advocate as defined seem to be at odds.

- Medicine's current concept of professionalism is not designed to encourage advocacy in progressive movements or the critical interrogation of racism within the medical profession itself.

- It is time to challenge traditional concepts of what constitutes professional behaviour in medicine so that physicians can be equipped to advocate for a society that supports health for all.

- Although tools for embedding antiracism training into medical programs exist, much work remains for Canadian institutions to firmly embed antiracism into medical education.

"role modelling"; 3 that is, trainees do not see the health advocate role embodied by their teachers.

In contrast, the role of physician as "professional" remains a constant pillar of medical education. Socialization theory posits that occupational training includes not only knowledge acquisition but also identity formation ${ }^{4}$ and, for medical learners, this has included messaging related to becoming a "neutral physician," where learners' social identities are suborned in pursuit of becoming an "impartial knower." Although this concept of professionalism does respect diversity, it is not designed to encourage advocacy in progressive movements, and particularly not the critical interrogation of racism within the medical profession itself.

Canadian medical education has relied heavily on lectures in the preclinical years and the apprenticeship model during clinical training, which, for trainees, means that the culture of what is considered professional in medicine is strongly influenced by the behaviour of their staff and seniors. ${ }^{6}$ Modelled behaviour forms an important part of the hidden curriculum. ${ }^{7}$ Learners' experience of professionalism in training programs is not race neutral, however. Racialized residents in Canadian surgical programs have reported that their competence was questioned more often than that of their gender-matched peers, and they felt less confident that their reports of discrimination (often itself considered to be an unprofessional act) would lead to appropriate action being taken. ${ }^{8}$ Indeed, the findings of a recent qualitative study of 
US physician-trainees considered underrepresented in medicine suggest that racialized students must actively work to dismantle harmful stereotypes to be able to align their professional (physician) and racial identities. ${ }^{9}$

Although medical training curricula certainly include race and racism as determinants of health, whether they adequately prepare trainees to act in solidarity with and to actively advocate for structural improvements for affected communities is less clear. Institutions have been offered an opportunity to reflect on their complicity in unjust structures through the recently released recorded comments made by health care professionals to Joyce Echaquan, an Indigenous woman who died in a Quebec hospital, as well as emerging evidence of the complex and disproportionate effects of the coronavirus disease 2019 pandemic on the lives of racialized people. ${ }^{10}$ Many institutions have offered statements condemning racism in medicine. ${ }^{11}$ Yet such institutions, if they are concerned with the public good, must also be willing to support physicians who are politically engaged to further antiracism as medical professionals. Advocacy activities - including publicly protesting, grassroots organizing and engaging in academic discourse - are all valid parts of physician identities.

One barrier to broadening the concept of medical professionalism may be the profession's timidity in tackling racism within its ranks. Rather than acknowledge the difficult issue of racism, institutions talk instead about increasing diversity. ${ }^{12,13}$ The Canadian Federation of Medical Students' broad definition of diversity - encompassing "diversity in culture, ethnicity, gender, sexuality, physical ability, geography, religion and socioeconomic status"13 - gives insight into how specifically naming and addressing racial inequity within the profession can become difficult. By focusing broadly on improving diversity, an institution can claim to have addressed the problem without even tackling racism, which may actually compound racial oppression.

Antiracism training in Canadian medical education is not well established, but there are many institutions that are actively engaged with this work. For example, the University of Manitoba Rady Faculty of Health Sciences has an Indigenous health curriculum that includes antiracism content, and the Temerty Faculty of Medicine at the University of Toronto recently stated plans to "expand antiracist education in our learning, research and clinical spaces and focus on cultural safety for Black and Indigenous learners across our institutions." Such initiatives support the idea that antiracism is an important part of medical education. Expanding service-learning programs to explicitly include social justice advocacy may serve to normalize this work as part of medical professional practice for nonracialized and racialized physicians alike.

Universalizing and normalizing a racial-justice approach to health care will foster better patient care. Professionalism itself must include advocacy. Although medical professionals may not agree with each other or their institutions, we are united in our obligations to the public good. As such, physicians must be supported in breaking free from narrow notions of professional behaviour to engage with the work of racial justice. We cannot be neutral when the stakes are as high as the health and well-being of our patients.

\section{References}

1. Frank JR, Snell L, Sherbino J, editors. CanMEDS 2015 Physician Competency Framework. Ottawa: Royal College of Physicians and Surgeons of Canada; 2015 (accessed 2020 July 11).

2. Gray A. The bias of "professionalism" standards. Palo Alto (CA): Stanford Social Innovation Review; 2019. Available: https://ssir.org/articles/entry/the_bias_of_ professionalism_standards (accessed 2020 July 12).

3. Boroumand S, Stein MJ, Jay M, et al. Addressing the health advocate role in medical education. BMC Med Educ 2020;20:28.

4. Hafferty FW. Professionalism and the socialization of medical students. In: Cruess RL, Cruess SR, Steinert Y, editors. Teaching Medical Professionalism. Cambridge (UK): Cambridge University Press; 2008:53-70.

5. Beagan BL. Neutralizing differences: producing neutral doctors for (almost) neutral patients. Soc Sci Med 2000;51:1253-65.

6. Byszewski A, Gill JS, Lochnan H. Socialization to professionalism in medical schools: a Canadian experience. BMC Med Educ 2015;15:204.

7. Lehmann LS, Sulmasy LS, Desai S, et al.; Professionalism and Human Rights Committee. Hidden curricula, ethics, and professionalism: optimizing clinical learning environments in becoming and being a physician: a position paper of the American College of Physicians. Ann Intern Med 2018;168:506-8.

8. Mocanu V, Kuper TM, Marini W, et al. Intersectionality of gender and visible minority status among general surgery residents in Canada. JAMA Surg 2020;155:e202828.

9. Wyatt TR, Rockich-Winston N, Taylor TR, et al. What does context have to do with anything? A study of professional identity formation in physician-trainees considered underrepresented in medicine. Acad Med 2020;95:1587-93.

10. Webb Hooper M, Nápoles AM, Pérez-Stable EJ. COVID-19 and racial/ethnic disparities. JAMA 2020;323:2466-7.

11. Canadian Federation of Medical Students statement in response to the death of Joyce Echaquan [news release]. Ottawa: Canadian Federation of Medical Students; 2020 Oct. 6. Available: www.cfms.org/news/2020/10/06/canadian -federation-of-medical-students-statement-in-response-to-the-death-of-joyce -echaquan (accessed 2020 Nov. 19).

12. Ahmad NJ, Shi M. The need for anti-racism training in medical school curricula. Acad Med 2017;92:1073.

13. Funnell S, Kitty D, Schipper S. Moving toward anti-racism. Can Fam Physician 2020;66:617.

14. TAHSN statement on anti-racism [news release]. Toronto: Temerty School of Medicine, University of Toronto; 2020 Oct. 9. Available: https://medicine.utoronto .ca/news/tahsn-statement-anti-racism (accessed 2020 Nov. 19).

\section{Competing interests: None declared.}

This article has been peer reviewed.

Affiliations: Department of Anesthesia (Sharda), Halton Healthcare - Oakville Trafalgar Memorial Hospital, Oakville, Ont.; Department of Anesthesia (Sharda), McMaster University, Hamilton Ont.; Department of Family Medicine (Dhara), Dalhousie University, Halifax, NS; Department of Anesthesia (Alam), Sunnybrook Health Sciences Centre; Department of Anesthesiology and Pain Medicine (Alam), and The Wilson Centre for Research in Medical Education (Alam), Faculty of Medicine, University of Toronto, Toronto, Ont.

Contributors: All of the authors contributed to the conception and design of the work, drafted the manuscript, revised it critically for important intellectual content, gave final approval of the version to be published and agreed to be accountable for all aspects of the work.

Content licence: This is an Open Access article distributed in accordance with the terms of the Creative Commons Attribution (CC BY-NCND 4.0) licence, which permits use, distribution and reproduction in any medium, provided that the original publication is properly cited, the use is noncommercial (i.e., research or educational use), and no modifications or adaptations are made. See: https://creativecommons .org/licenses/by-nc-nd/4.0/

Correspondence to: Saroo Sharda, ssharda@haltonhealthcare.com 